\title{
ON SOFT COMPUTING TECHNIQUES IN VARIOUS AREAS
}

\author{
Santosh Kumar Das ${ }^{1}$, Abhishek Kumar ${ }^{2}$, Bappaditya Das ${ }^{3}$ and \\ A.P.Burnwal ${ }^{4}$ \\ ${ }^{1,3}$ Department of Computer Science and Engineering, Dr. B. C. Roy \\ Engineering College, Durgapur-713206, W.B, India \\ sunsantosh2007@rediffmail.com¹, bappaditya.dasabcrec.org ${ }^{3}$ \\ ${ }^{2}$ Department of Electronics \& Communication Engineering, University College \\ of Engineering Technology, Vinoba Bhave University, Hazaribag-825301, \\ Jharkhand, India \\ abhishekec02@gmail. com \\ ${ }^{4}$ Department of Master of Computer Applications, Guru Gobind Singh \\ Educational Society's Technical Campus, Bokaro-827013, Jharkhand, India \\ apburnwaleyahoo.com
}

\begin{abstract}
Soft Computing refers to the science of reasoning, thinking and deduction that recognizes and uses the real world phenomena of grouping, memberships, and classification of various quantities under study. As such, it is an extension of natural heuristics and capable of dealing with complex systems because it does not require strict mathematical definitions and distinctions for the system components. It differs from hard computing in that, unlike hard computing, it is tolerant of imprecision, uncertainty and partial truth. In effect, the role model for soft computing is the human mind. The guiding principle of soft computing is: Exploit the tolerance for imprecision, uncertainty and partial truth to achieve tractability, robustness and low solution cost. The main techniques in soft computing are evolutionary computing, artificial neural networks, and fuzzy logic and Bayesian statistics. Each technique can be used separately, but a powerful advantage of soft computing is the complementary nature of the techniques. Used together they can produce solutions to problems that are too complex or inherently noisy to tackle with conventional mathematical methods. The applications of soft computing have proved two main advantages. First, it made solving nonlinear problems, in which mathematical models are not available, possible. Second, it introduced the human knowledge such as cognition, recognition, understanding, learning, and others into the fields of computing. This resulted in the possibility of constructing intelligent systems such as autonomous self-tuning systems, and automated designed systems. This paper highlights various areas of soft computing techniques.
\end{abstract}

\section{KEYWORDS}

Soft Computing, Fuzzy Logic, Neuro Computing

\section{INTRODUCTION}

In real world, we have many problems which we have no way to solve logically, or problems which could be solved theoretically but actually impossible due to its requirement of huge resources and huge time required for computation. For these problems, methods motivated by

Rupak Bhattacharyya et al. (Eds) : ACER 2013, 
nature sometimes work very efficiently and effectively. Although the solutions obtained by these methods do not always equal to the mathematically strict solutions, a near optimal solution is sometimes enough in most practical purposes. These biologically inspired methods are called Soft Computing. Soft Computing is an umbrella term for a collection of computing techniques. The term was first coined by Professor Lotfi Zadeh [1], who developed the concept of fuzzy logic.

Soft computing is based on natural as well as artificial ideas. It is referred as a computational intelligence. It differs from conventional computing that is hard computing. It is tolerance of imprecision, uncertainty, partial truth to achieve tractability, approximation, robustness, low solution cost, and better rapport with reality. In fact the role model for soft computing is human mind. It refers to a collection of computational techniques in computer science, artificial intelligence, machine learning applied in engineering areas such as Aircraft, spacecraft, cooling and heating, communication network, mobile robot, inverters and converters, electric power system, power electronics and motion control etc. Traditionally soft computing has been comprised by four technical disciplines. The first two, probabilistic reasoning (PR), and fuzzy logic (FL) reasoning systems, are based on knowledge-driven reasoning. The other two technical disciplines, Neuro Computing (NC) and Evolutionary Computing (EC), are data - driven search and optimization approaches, which is shown in the fig 1.

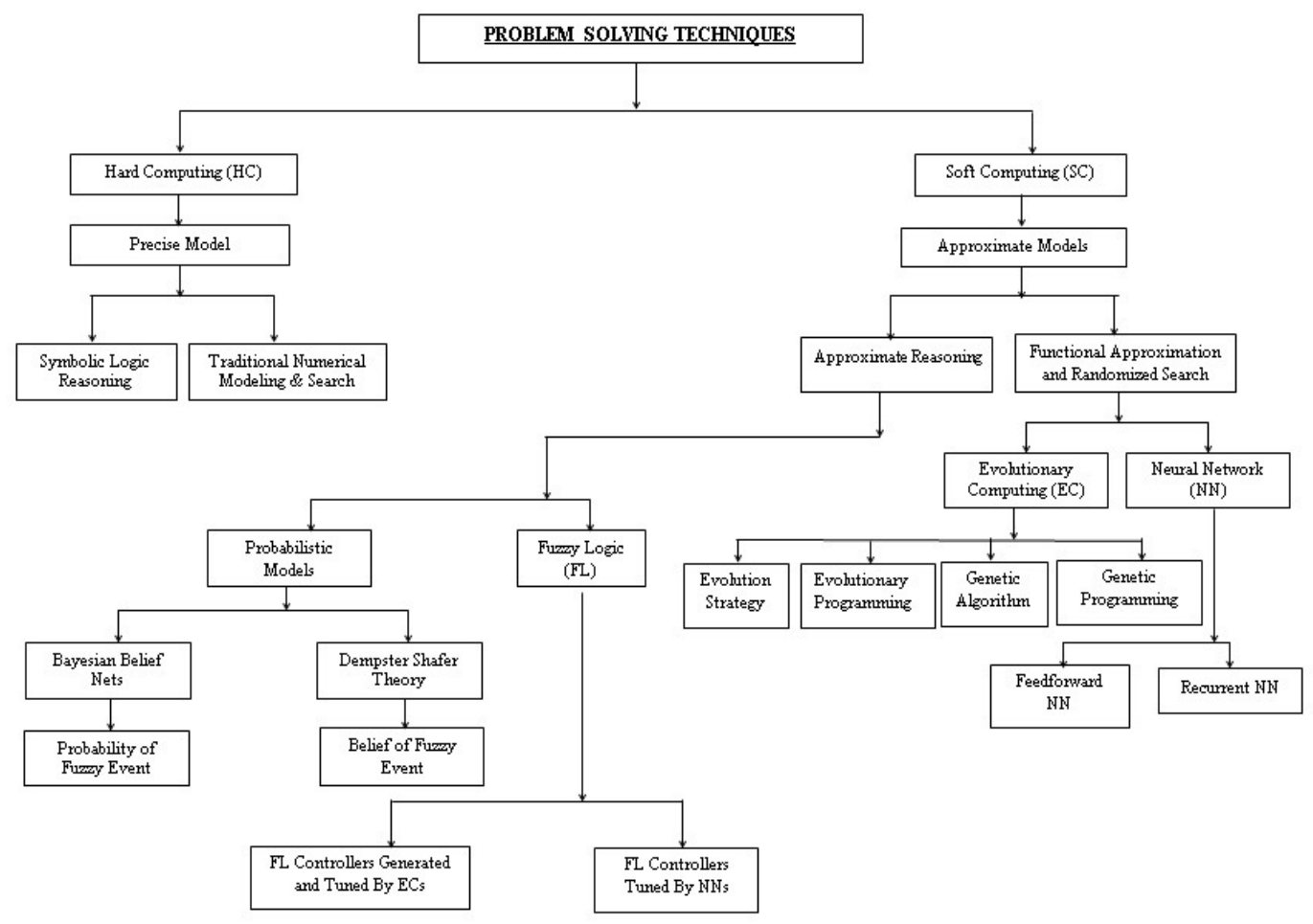

\section{SoFT COMPUTING}

Soft computing is not a mélange. Rather, it is a partnership is which each of the constituent contributes a distinct methodology for addressing problem in its domain. In this perspective, the principal constituent methodologies in soft computing are complementary rather than competitive. In fact, soft computing's main characteristic is its intrinsic capability to create hybrid systems that are based on the integration of constituent technologies. This integration provides complementary reasoning and searching methods that allow us to combine domain knowledge and empirical data to develop flexible computing tools and solve complex problems. Hybrid 
computing is the combination of hard computing and soft computing which having their inherent advantages and disadvantages. To get the advantages of both these techniques their individuals limitations are reduced for solving a problem more efficiently by Hybrid computing. Hybrid soft computing models have been applied to a large number of classification, prediction, and control problems.

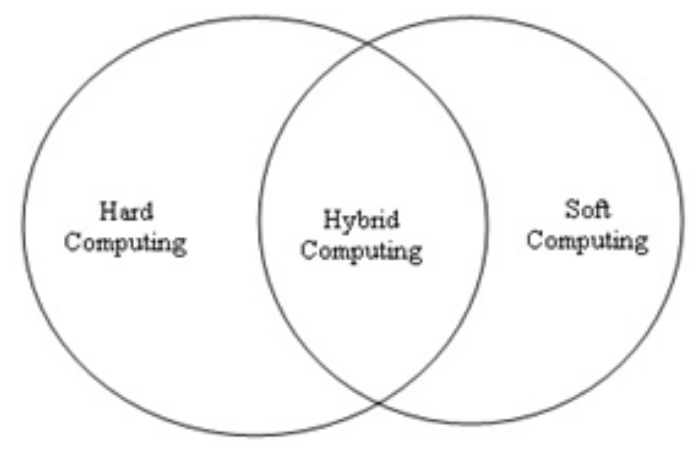

Fig 2

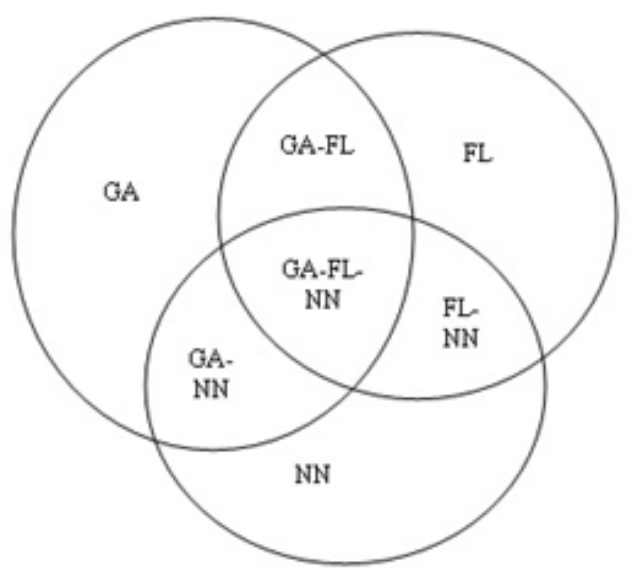

Fig 3

Figures $2 \& 3$ show schematic diagram of intersections of members of soft computing family \& hybrid computing scheme.

\section{APPLICATION AREAS OF SOFT COMPUTING}

Soft computing techniques have become one of promising tools that can provide practice and reasonable solution. Soft computing techniques are used in different fields shown in fig 4

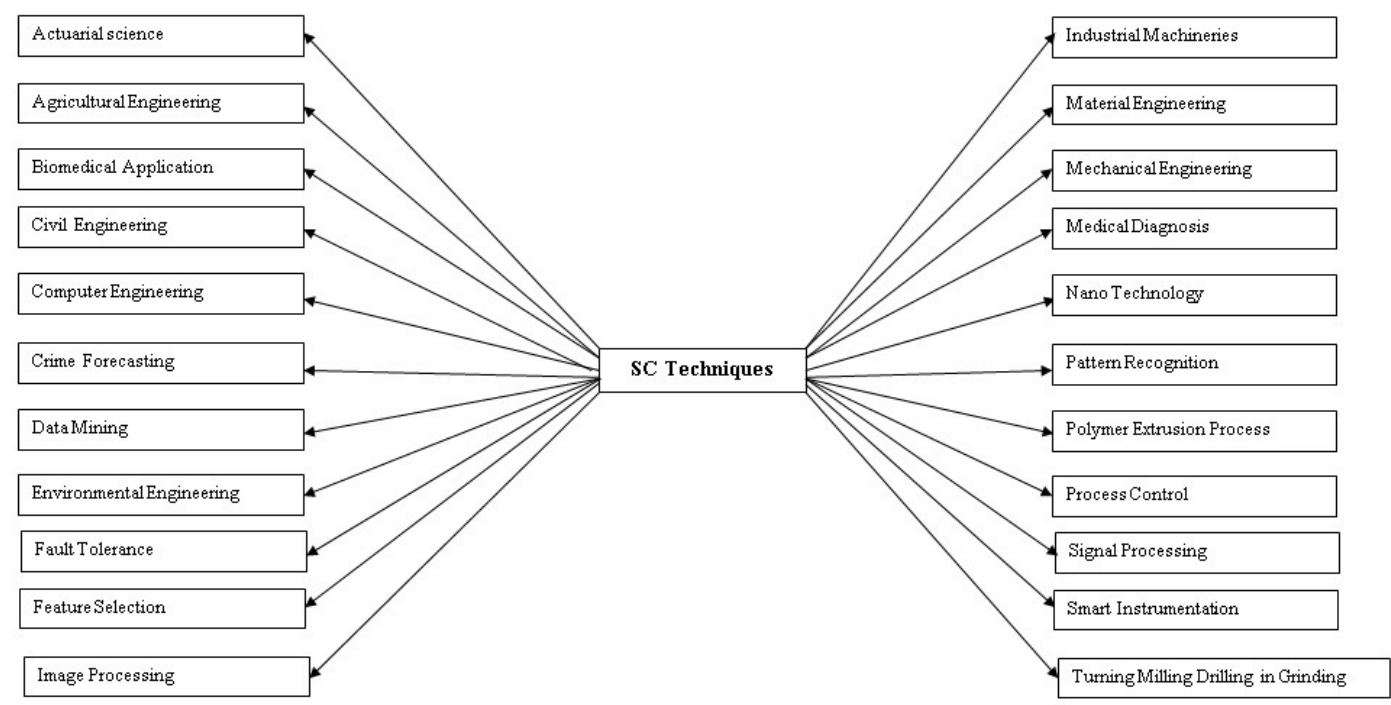

Fig 4 


\subsection{Actuarial Science}

Actuarial science is the discipline that applies mathematical and statistical methods to evaluate risk in the insurance and finance industries. Actuarial science includes a number of interrelating subjects, including probability, mathematics, statistics, finance, economics, financial economics, and computer programming. Historically, actuarial science used deterministic models in the construction of tables and premiums.

\subsection{Agricultural Engineering}

Agricultural engineering is the engineering discipline that applies engineering science and technology to agricultural production and processing. Agricultural engineering combines the disciplines of animal biology, plant biology, and mechanical, civil, electrical and chemical engineering principles with knowledge of agricultural principles.

\subsection{Biomedical Application}

Biomedical application is a design concept to medicine and biology. This field seeks to close the gap between engineering and medicine: It combines the design and problem solving skills of engineering with medical and biological sciences to advance healthcare treatment, including diagnosis, monitoring, treatment and therapy.

\subsection{Civil Engineering}

Civil engineering is a professional engineering discipline that deals with the design, construction, and maintenance of the physical and naturally built environment, including works like roads, bridges, canals, dams, and buildings. Civil engineering takes place on all levels: in the public sector from municipal through to national governments, and in the private sector from individual homeowners through to international companies.

\subsection{Computer Engineering}

Computer engineering is a discipline that integrates several fields of electrical engineering and computer science required to develop computer systems. Computer engineers usually have training in electronic engineering, software design, and hardware-software integration instead of only software engineering or electronic engineering. Computer engineers are involved in many hardware and software aspects of computing, from the design of individual microprocessors, personal computers, and supercomputers, to circuit design. This field of engineering not only focuses on how computer systems themselves work, but also how they integrate into the larger picture.

\subsection{Crime Forecasting}

Crime forecast is a planning tool that helps to manage crime in our society in different way. Crime is the breaking of rules or laws for which some governing authority can ultimately prescribe a conviction. Crimes may also result in cautions, rehabilitation or be unenforced. By the help of crime forecast we can reduce crime in our societies. 


\subsection{Data Mining}

Data mining is a subfield of computer science which is the computational process of discovering patterns in large data sets involving methods at the intersection of artificial intelligence, machine learning, statistics, and database systems. The overall goal of the data mining process is to extract information from a data set and transform it into an understandable structure for further use.

\subsection{Environmental Engineering}

Environmental engineering is the integration of science and engineering principles to improve the natural environment like air, water, and/or land resources, to provide healthy water, air, and land for human habitation like house or home and for other organisms, and to remediate pollution sites.

\subsection{Fault-Tolerance}

Fault-tolerance is the property that enables a system to continue operating properly in the event of the failure of some of its components. If its operating quality decreases at all, the decrease is proportional to the severity of the failure, as compared to a naïvely-designed system in which even a small failure can cause total breakdown. Fault-tolerance is particularly sought-after in high-availability or life-critical systems.

\subsection{Feature Selection}

In machine learning and statistics, feature selection, also known as variable selection, attribute selection or variable subset selection, is the process of selecting a subset of relevant features for use in model construction. Feature selection techniques are a subset of the more general field of feature extraction. Feature extraction creates new features from functions of the original features, whereas feature selection returns a subset of the features.

\subsection{Image Processing}

In imaging science, image processing is any form of signal processing for which the input is an image, such as a photograph or video frame; the output of image processing may be either an image or a set of characteristics or parameters related to the image. Most image-processing techniques involve treating the image as a two-dimensional signal and applying standard signalprocessing techniques to it.

\subsection{Industrial Machineries}

Industries machineries are tool that consists of one or more parts, and uses energy to achieve a particular goal. Machines are usually powered by mechanical, chemical, thermal, or electrical means, and are frequently motorized. This is used in mechanical engineering.

\subsection{Materials Engineering}

Materials engineering is an interdisciplinary field applying the properties of matter to various areas of science and engineering. This scientific field investigates the relationship between the structure of materials at atomic or molecular scales and their macroscopic properties. It incorporates elements of applied physics and chemistry. 


\subsection{Mechanical Engineering}

Mechanical engineering is a discipline of engineering that applies the principles of physics and materials science for analysis, design, manufacturing, and maintenance of mechanical systems. It is the branch of engineering that involves the production and usage of heat and mechanical power for the design, production, and operation of machines and tools.

\subsection{Medical diagnosis}

Medical diagnosis refers both to the process of attempting to determine or identify a possible disease and to the opinion reached by this process. From the point of view of statistics the diagnostic procedure involves classification tests.

\subsection{Nano Technology}

Nanotechnology is the manipulation of matter on an atomic and molecular scale. Generally, nanotechnology works with materials, devices, and other structures with at least one dimension sized from 1 to 100 nanometers. Nanotechnology entails the application of fields of science as diverse as surface science, organic chemistry, molecular biology, semiconductor physics, micro fabrication, etc.

\subsection{Pattern Recognition}

Pattern recognition generally aim to provide a reasonable answer for all possible inputs and to perform "most likely" matching of the inputs, taking into account their statistical variation. Pattern recognition is studied in many fields, including psychology, psychiatry, and ethology, cognitive science, and traffic flow and computer science.

\subsection{Polymer Extrusion Process}

A polymer is a chemical compound or mixture of compounds consisting of repeating structural units created through a process of polymerization. Polymers are studied in the fields of biophysics and macromolecular science, and polymer science.

Extrusion is a process used to create objects of a fixed, cross-sectional profile. A material is pushed or drawn through a die of the desired cross-section. The two main advantages of this process over other manufacturing processes are its ability to create very complex cross-sections and work materials that are brittle, because the material only encounters compressive and shear stresses.

\subsection{Process Control}

Process control is a statistics and engineering discipline that deals with architectures, mechanisms and algorithms for maintaining the output of a specific process within a desired range. It is extensively used in industry and enables mass production of continuous processes such as oil refining, paper manufacturing, chemicals, power plants and many other industries. Process control enables automation, with which a small staff of operating personnel can operate a complex process from a central control room. 


\subsection{Signal Processing}

Signal processing is an area of systems engineering, electrical engineering and applied mathematics that deals with operations on or analysis of signals, or measurements of time-varying or spatially varying physical quantities. Types of signals are sound, images, and sensor data, for example biological data such as electrocardiograms, control system signals, telecommunication transmission signals, and many others.

\subsection{Smart Instrumentation}

As intelligent devices become ubiquitous the challenge is to connect sensors and actuators through smart systems. A major issue is the growing number of communication protocols, with no single standard.

The challenge is to intelligently connect smart instrumentation so that devices can communicate across multiple protocols. At the same time, increases in the volume and importance of data means that privacy, security and robustness of systems is paramount.

\subsection{Turning Milling Drilling in Grinding}

Turning is a machining process in which a cutting tool, typically a non-rotary tool bit, describes a helical tool path by moving more or less linearly while the work piece rotates.

Milling is the machining process of using rotary cutters to remove material from a work piece advancing in a direction at an angle with the axis of the tool. It covers a wide variety of different operations and machines, on scales from small individual parts to large, heavy-duty gang milling operations.

Drilling is a cutting process that uses a drill bit to cut or enlarge a hole of circular cross-section in solid materials. The drill bit is a rotary cutting tool, often multipoint. The bit is pressed against the work piece and rotated at rates from hundreds to thousands of revolutions per minute. This forces the cutting edge against the work piece, cutting off chips from what will become the hole being drilled.

Grinding is used to finish work pieces that must show high surface quality and high accuracy of shape and dimension. 


\section{SHORT DESCRIPTION OF SOFT COMPUTING IN DifFERENT AREAS}

\begin{tabular}{|c|l|l|l|}
\hline $\begin{array}{c}\text { Sl.no } \\
\cdot\end{array}$ & \multicolumn{1}{|c|}{ Field of applications } & $\begin{array}{c}\text { Soft computing } \\
\text { components }\end{array}$ & \multicolumn{1}{|c|}{ References } \\
\hline 1 & Aircraft and air traffic & NN, FL, EC & {$[2],[3]$} \\
\hline 2 & Communication networks & FL, NN, EC & {$[4],[5],[6],[7]$} \\
\hline & Control and Monitoring & EC, FL, NN & $\begin{array}{l}{[8],[9],[10],} \\
{[11],[12],[13]}\end{array}$ \\
\hline 3 & Cooling and Heating & FL, NN, EC & $\begin{array}{l}{[14],[15],[16],[17],} \\
{[18],[19]}\end{array}$ \\
\hline 4 & & FL, NN & {$[20],[21]$} \\
\hline 5 & Data communications & ANN, FL & {$[22]$} \\
\hline 6 & Data Security & FL, NN & {$[23],[24]$} \\
\hline 7 & Induction Motor Drives & FL, NN & {$[25],[26]$} \\
\hline 8 & Inverters and Converters & FL, NN & {$[27],[28]$} \\
\hline 9 & Manufacturing Technologies & FL, NN & {$[29]$} \\
\hline 10 & Mobile Robots & EC, FL & {$[30]$} \\
\hline 11 & Multi-Agent Robots & GA & {$[31]$} \\
\hline 12 & Network Optimization & EC & {$[32]$} \\
\hline 13 & Power Control & ANN & {$[33]$} \\
\hline 14 & Radio Planning & ANN & {$[34]$} \\
\hline 15 & Resource Allocation & ANN, FL, EA & {$[35]$} \\
\hline 16 & Satellite Imaging & ANN & {$[36]$} \\
\hline 17 & Scheduling & NN, FL, & {$[37],[38]$} \\
\hline 18 & Spacecraft & FL, NN & {$[39]$} \\
\hline 19 & Steel Process Industry & FL & {$[40]$} \\
\hline 20 & Switched Reluctance Motor Drives & & \\
\hline & & & \\
\hline
\end{tabular}

\section{CONCLUSION}

As the development of soft computing progresses in several disciplines including physics, chemistry, biology and material science, computer scientists must be aware of their roles and brace themselves for the greater advancement of soft computing in the future. This paper has outlined different areas of soft computing. The successful applications of soft computing and the rapid growth suggest that the impact of soft computing will be felt increasingly in coming years. It encourages the integration of soft computing techniques and tools into both every day and advanced applications. It is hoped that this gentle review will benefit computer scientist who are keen to contribute their works to the field of soft computing.

\section{REFERENCES}

[1] Lotfi A. Zadeh (1994), "Fuzzy Logic, Neural Networks and Soft Computing", Communication of the ACM, 37(3), pp77-84.

[2] M. R. Napolitano, J. L. Casanova, D. A. Windon, II, B. Seanor, and D. Martinelli (1999), "Neural and fuzzy reconstructors for the virtual flight data recorder," IEEE Trans. Aerosp. Electron. Syst., vol. 35, no. 1, pp. 61-71

[3] N. L. Schneider, S. Narayanan, and C. Patel (2000), "Integrating genetic algorithms and interactive simulations for airbase logistics planning," in Soft Computing in Industrial Applications, Y. Suzuki, S. Ovaska, T. Furuhashi, R. Roy, and Y. Dote, Eds. London, U.K.: Springer- Verlag, pp. 309-317.

[4] E. Gelenbe, I.W. Habib, S. Palazzo, and C. Douligeris (2000), "Guest editorial: Intelligent techniques in high speed networks,” IEEE J. Select. Areas Commun., vol. 18, pp. 145-149. 
[5] G. Chakraborty and B. Chakraborty (1999), "A genetic algorithm approach to solve channel assignment problem in cellular radio networks," in Proc. IEEE Midnight-Sun Workshop Soft Computing Methods in Industrial Applications, Kuusamo, Finland, pp. 34-39.

[6] B. Dengiz, F. Altiparmak, and A. E. Smith (1997), "Local search genetic algorithm for optimal design of reliable networks," IEEE Trans. Evol. Comput., vol. 1, pp. 179-188.

[7] X. M. Gao, X. Z. Gao, J. M. A. Tanskanen, and S. J. Ovaska (1997), "Power prediction in mobile communication systems using an optimal neural-network structure," IEEE Trans. Neural Networks, vol. 8, pp. 1446-1455.

[8] A. Kamiya, K. Kawai, I. Ono, and S. Kobayashi (1999), "Adaptive-edge search for power plant start-up scheduling,” IEEE Trans. Syst., Man, Cybern. C, vol. 29, pp. 518-530.

[9] J. Wen, S. Cheng, and O. P. Malik (1998), "A synchronous generator fuzzy excitation controller optimally designed with a genetic algorithm,” IEEE Trans. Power Syst., vol. 13, pp. 884-889.

[10] C.-W. Liu, M.-C. Su, S.-S. Tsay, and Y.-J. Wang (1999), "Application of a novel fuzzy neural network to real-time transient stability swings prediction based on synchronized phasor measurements," IEEE Trans. Power Syst., vol. 14, pp. 685-692.

[11] A. L. B. do Bomfim, G. N. Taranto, and D. M. Falcano (2000), "Simultaneous tuning of power system damping controllers using genetic algorithms,” IEEE Trans. Power Syst., vol. 15, pp. 163-169.

[12] R. Segal, M. L. Kothari, and S. Madnani (2000), "Radial basis function (RBF) network adaptive power systems stabilizer," IEEE Trans. Power Syst., vol. 15, pp. 722-727.

[13] H.-J. Cho and J.-K. Park (1997), “An expert system for fault selection diagnosis of power systems,” IEEE Trans. Power Syst., vol. 12, pp. 342-348.

[14] J. H. Kim, K. S. Kim, M. S. Sim, K. H. Han, and B. S. Ko (1999), "An application of fuzzy logic to control the refrigerant distribution for the multi type air conditioner," in Proc. IEEE Int. Fuzzy Systems Conf., vol. 3, Seoul, Korea, pp. 1350-1354.

[15] T. Nitta (1993), "Applications of neural networks to home appliances," in Proc. IEEE Int. Joint Conf. Neural Networks, Nagoya, Japan, 1993, pp. 1056-1060.

[16] M. Shim, S. Seong, B. Ko, and M. So (1999), "Application of evolutionary computations at LG Electronics," in Proc. IEEE Int. Fuzzy Systems Conf., vol. 3, Seoul, Korea, pp. 1802-1806.

[17] N.Wakami, S. Araki, and H. Nomura (1993), "Recent applications of fuzzy logic to home appliances," in Proc. IEEE Int. Conf. Industrial Electronics, Control, and Instrumentation, Maui, HI, pp. 155-160.

[18] M. Becker, D. Oestreich, H. Hasse, and L. Litz (1994), "Fuzzy control for temperature and humidity in refrigerator systems," in Proc. 3rd IEEE Conf. on Control Applications, Glasgow, Scotland, pp. 16071612.

[19] R. Zhu, B. Tian, Q. Wang, and G. Dai (1997), “Application of fuzzy logic in home appliance: Gas heater controller design,” in Proc. IEEE Int. Conf. Intelligent Processing Systems, pp373-376.

[20] C. E. Cramer and E. Gelenbe (2000), "Video quality and traffic QoS in learning-based sub-sampled and receiver-interpolated video sequences," IEEE J. Select. Areas Commun., 18, pp150-167.

[21] J. M. Jou and P.-Y. Chen (1999), "A fast and efficient lossless data-compression method," IEEE Trans. Commun., 47, pp1278-1283.

[22] Mar J., Yow-Cheng Yeh, I-Fan Hsiao (2010), "An ANFIS-IDS against deauthentication DOS attacks for a WLAN," Int'l Symp. On Information Theory and its app. pp 548-553.

[23] P. Z. Grabowski, M. P. Kazmierkowski, B. K. Bose, and F. Blaabjerg (2000), "A simple direct-torque neuro-fuzzy control of PWM-inverter-fed induction motor drive,” IEEE Trans. Ind. Electron., 47, pp863870.

[24] L. Ben-Brahim, S. Tadakuma, and A. Akdag (1999), "Speed control of induction motor without rotational transducers," IEEE Trans. Ind. Applicat., 35, pp844-850.

[25] Y.-Y. Zou and S.-Y. Lin (1998), "Fuzzy-tuning current-vector control of a three-phase PWM inverter for high-performance AC drives,” IEEE Trans. Ind. Electron., 45, pp782-791.

[26] R. W. Pretorius, I. S. Shaw, and J. D. van Wyk (2000), "A neural-network based controller for the costeffective operation of a hybrid compensator for conactiva power,” IEEE Trans. Ind. Electron., 47, pp1201227.

[27] G. G. Yen and K.-C. Lin (2000), "Wavelet packet feature extraction for vibration monitoring,” IEEE Trans. Ind. Electron., 47, pp650-667.

[28] D. Kim (2000), "An implementation of fuzzy logic controller on the reconfigurable FPGA system," IEEE Trans. Ind. Electron., 47, pp703-715.

[29] P. Baranyi, I. Nagy, P. Korondi, and H. Hashimoto (2000), "General guiding model for mobile robots and its complexity reduced neuro-fuzzy approximation,” in Proc. IEEE Int. Conf. Fuzzy Systems, San Antonio, TX, pp 1029-1032.

[30] A. Ishiguro, Y. Shirai, T. Kondo, and Y. Uchikawa (1996), "Immunoid: An architecture for behavior arbitration based on the immune networks," in Proc. Int. Conf. Intelligent Robotics and Systems, Osaka, Japan, pp 1730-1738. 
[31] Chuan-Kang Ting, Chung-Nan Lee, Hui-Chun Chang, Jain-Shing Wu (2009), "Wireless Heterogenous Transmitter Placement Using Multi-objective Variable-Length Genetic Algorithm," IEEE Trans. on Systems, Man and Cybernetics, 39(4), pp 945-958.

[32] Won Jay Song and Byung Ha Ahn (2002), "Distributed power control using the simultaneous mutation of genetic algorithms in cellular radio systems," proc. of int'l conf. of IT: Coding and computing, South Korea, pp 361-364.

[33] Stocker K. E, Alcatel Sel, Stuttgart (1993), "Neural Network Approach to Prediction of terrestrial wave propagation for mobile radio," IEEE proc. on Microwaves, Antennas and Propagation, 140(4), pp 315-320

[34] Isvarya Luckshmi, Visalakshi, P., Karthikeyan, N.K. (2011), "Intelligent Schemes for Bandwidth Allocation in Cellular Mobile Networks" international Conference on Process Automation, Control and Computing (PACC), pp 1-6.

[35] Kaghed N.H., Abbas, T.A., Hussein Ali, S. (2006), "Design and Implementation of Classification System for Satellite Images based on Soft Computing Techniques," 2nd ICTTA Conference, pp 430-436.

[36] Yu-Ju Shen and Ming-Shi Wang (2007), "Optimizing satellite broadcast Scheduling problem using Competitive Hopfield Neural Network," Wireless Tel. Symposium, pp.1-6.

[37] A. Martin-Alvarez, R. Volpe, S. Hayati, and R. Petras (1999), "Fuzzy reactive piloting for continuous driving of long range autonomous planetary micro-rovers," in Proc. IEEE Aerospace Conf., 2, pp127-135.

[38] P. J. Werbos (1993), "Neuro-control and elastic fuzzy logic: Capabilities, concepts, and applications," IEEE Trans. Ind. Electron., 40, pp 170-180.

[39] G. Bloch, F. Sirou, V. Eustache, and P. Fatrez (1997), "Neural intelligent control for a steel plant," IEEE Trans. Neural Networks, 8, pp 910-918.

[40] A. D. Cheok and N. Ertugrul (1999), "Use of fuzzy logic for modeling, estimation, and prediction in switched reluctance motor drives," IEEE Trans. Ind. Electron., 46, pp 1207-1224.

\section{AUTHORS}

Santosh Kumar Das obtained his BCA degree from IGNOU in 2006. He completed MCA degree in 2009 and he is pursuing M-Tech in CSE from Dr. B. C. Roy Engineering College, Durgapur (W.B), India. He has altogether 5 international/national journals/conferences to his credit. His research interests includes in the areas of Soft Computing, Mathematics and Wireless Communication

ABHISHEK KUMAR currently pursuing B-Tech final year in ECE Department from UCET, VBU, Hazaribag (Jharkhand). He has altogether 5 international/national journals/conferences to his credit.

BAPPADITYA DAS Assistant Professor in the Department of CSE of Dr. B.C. Roy Engineering College, Durgapur, West Bengal, INDIA. He had done his M-Tech in CSE from University of Calcutta. He passed B-Tech in CSE from University of Calcutta. He passed B.Sc in Physics Hons. from University of Calcutta. He is currently working toward the Ph.D. degree at University of Kalyani. His area of interest is on Wireless Sensor Network, Mobile Computing, Algorithms, Cryptography etc

A. P. BURNWAL obtained his MSc and Ph.D. degrees in mathematics. He is life member in different society like "Indian Science of Congress Association" Kolkata, "Bharata Ganita Prarisad" Lucknow, "International Society for Ecological Communications" S. K. University. He has 25 international/national journals/conferences to his credit. And currently he is Professor in MCA Department of GGSESTC, Kandra, Chas, Bokaro, Jharkhand, INDIA.

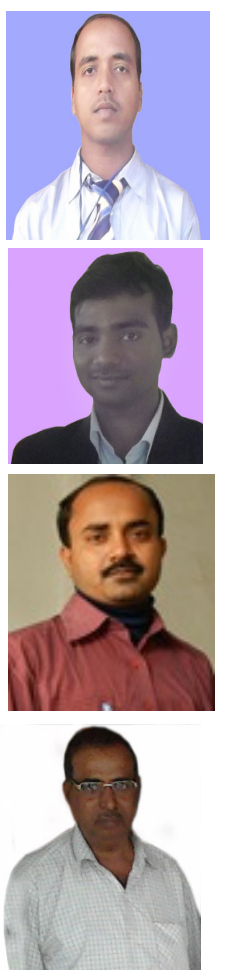

